\title{
Influence of Vehicle Suspension Parameters on its Braking Properties
}

\author{
Anna Dmitrieva \\ Institute of Engineering Sciences \\ Pskov State University \\ Pskov, Russia \\ anna-listratova@rambler.ru \\ Evgeny Seleznev \\ Institute of Engineering Sciences \\ Pskov State University \\ Pskov, Russia \\ evgeniys84@yandex.ru
}

\author{
Alexander Enaev \\ Institute of Engineering Sciences \\ Pskov State University \\ Pskov, Russia \\ enaa53@mail.ru \\ Tatyana Klets \\ Institute of Humanities and Linguistic \\ Communications \\ Pskov State University \\ Pskov, Russia \\ kte63@yandex.ru
}

\author{
Vladimir Timofeev \\ Institute of Engineering Sciences \\ Pskov State University \\ Pskov, Russia \\ timofeev1097@yandex.ru
}

\begin{abstract}
The paper focuses on the study of the performance of elastic and damping parameters of the car suspension. The problem of arising vibrations of the sprung and unsprung vehicle masses on the braking process is considered. The article presents theoretical models of vehicle braking taking into account the oscillations of the vehicle's sprung masses. The research results will make it possible to establish the relationship between the suspension parameters and the estimated parameters of braking properties, to supplement the "driver - car - road" system, and also to more accurately assess the active safety of vehicles associated with braking dynamics.
\end{abstract}

Keywords - car braking, mathematical model, sprung mass, vibrations.

\section{INTRODUCTION}

A car as a mechatronic object and a complex technical system has a number of operational properties, which, in the theory of car movement, are divided into two main groups - associated and not associated with the movement of the car. Also, in the classification of operational properties, there are those that affect the active and passive safety of the car [1]. According to the terminology, in the automotive industry, passive safety is a combination of properties that reduce the severity of the consequences of road accidents, and its main requirement is the design of the outer surfaces and elements of the car, in which the probability of damage to the driver and passengers by these elements in the event of a road traffic accident could be minimal [1], [2].
Active safety refers to properties designed to minimize the likelihood of a road traffic accident. Its provision is a priority task in the formation of road safety. Active safety includes several operational properties that allow you to confidently drive a car: accelerate and decelerate with the required intensity, as well as perform maneuvers required by the road situation. The most important are braking properties, and they account for $41.3 \%$ of the active safety of vehicles [2], [3].

The braking process of a car is dynamic and there are many factors affecting the braking performance, but in the theory of vehicle motion, the brake dynamics is considered under idealized conditions, corresponding to braking on a flat road. However, in the process of braking on an uneven road, under the influence of road irregularities, the car makes longitudinal and angular vibrations, which lead to a change in the indicators of the braking properties of the car.

\section{VIBRATION SYSTEM OF THE CAR AND SUSPENSION PARAMETERS}

The car is an oscillatory system that determines the smoothness of the vehicle and affects almost all performance properties.

To determine the effect of vibration of a car on braking properties, Fig. 1 shows a diagram of an oscillatory system, which is equivalent to a car when braking. The presented oscillatory system differs from the generally 
accepted one in the theory of oscillations and smoothness of cars in that braking forces are applied in the contact of the wheels with the supporting surface, causing an inertial force applied at the center of gravity.

The designations on the diagram are generally accepted in the theory of oscillations [4], [5]: M - sprung mass of the vehicle; $c_{1,2}$ - reduced coefficient of normal suspension stiffness; $\eta_{1,2}$ - reduced coefficient of inelastic resistance of the suspension; $\mathrm{q}_{1,2}(\mathrm{t})$ - the current values of the ordinates of the road surface micro-profile in the contact of the wheels in time; $\mathrm{z}_{1,2}(\mathrm{t})$ - the values of the vertical displacements of the sprung masses; $\mathrm{J}_{\mathrm{y}}$ - moment of inertia of the vehicle's sprung masses relative to the central transverse axis $\mathrm{O} ; \mathrm{P}_{\tau 1,2}$ - braking forces applied in the contact of the wheels; $\mathrm{R}_{\mathrm{z} 1,2}$ - normal reaction in the contact of the wheels with the supporting surface; $F_{j}$ is the inertial force of the total mass of the vehicle during braking; $\mathrm{r}_{1,2}$ - pair of forces equivalent to the moment of braking forces and inertial force; L - vehicle base; $\mathrm{a}, \mathrm{b}$ distance from the center of gravity to the vertical planes of the front and rear unsprung masses; $h_{0}$ is the height of the vehicle's center of gravity above the center line of the road support surface.

Indices 1 and 2 mark the parameters belonging to the front and rear suspensions, respectively.

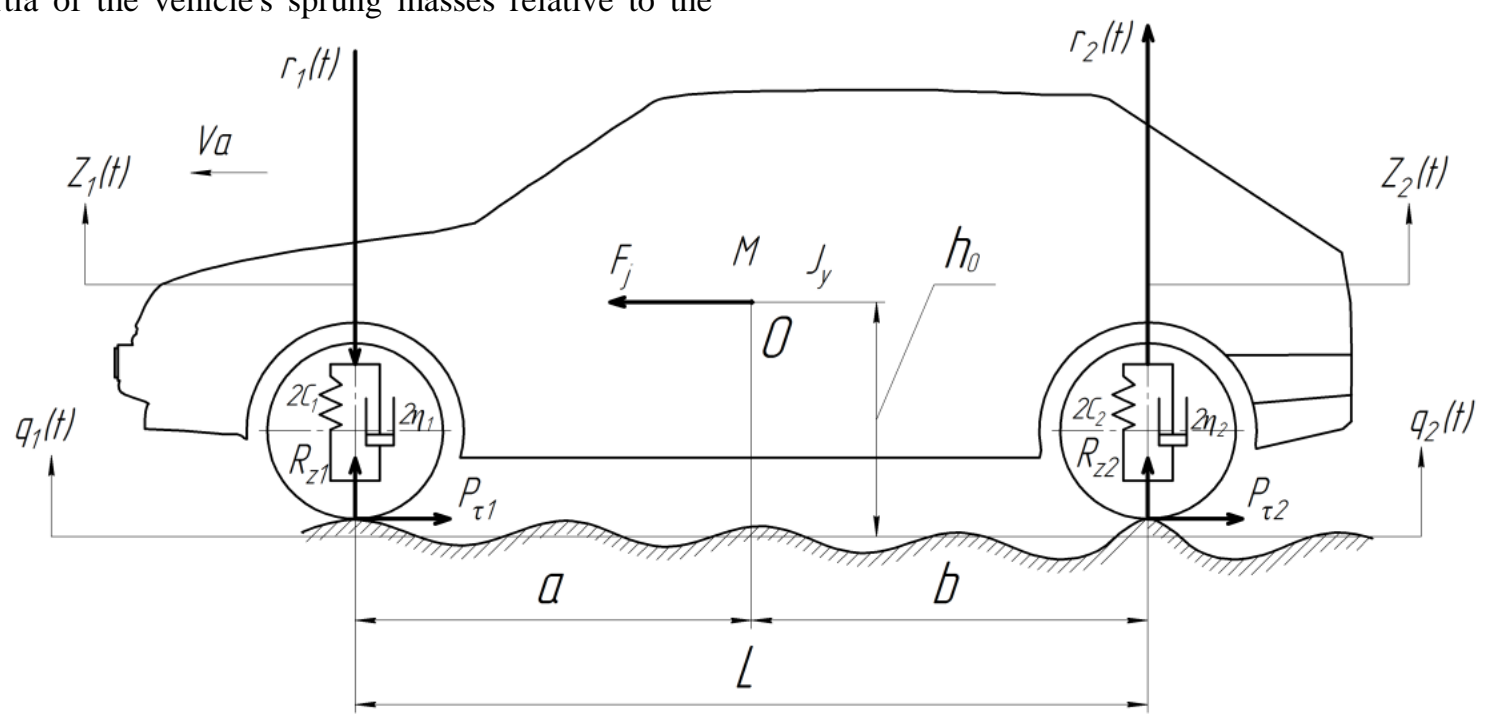

Fig. 1. Scheme of the oscillatory system, equivalent to the car when braking

This oscillatory system is simplified due to the fact that the vibrations of the sprung mass are dominant, and the influence of high-frequency vibrations of the unsprung masses with a relatively small amplitude can be neglected. Therefore, unsprung masses are excluded from consideration, and the reduced stiffness coefficients are introduced to take into account the elastic elements [4], [5]:

$$
c_{1,2}=\frac{c_{p 1,2} c_{t 1,2}}{c_{p 1,2}+c_{t 1,2}}
$$

Where $c_{s 1,2}$ is the coefficient of normal stiffness of the suspension; $c_{t 1,2}$ is the coefficient of normal stiffness of tires.

Combining in the same way the inelastic resistance of the suspension and tires and considering it proportional to the deformation rate, following the example of an already united elastic element, the damping properties of the above system (Fig. 1) will be estimated by the coefficient of inelastic resistance $\eta_{1.2}$.

The movement of the rear and front sprung masses of the vehicle during braking is described by the system of equations:

$$
\left\{\begin{array}{c}
M_{1} \ddot{z}_{1}+\eta_{1}\left(\dot{z_{1}}-\dot{q}_{1}\right)+c_{1}\left(z_{1}-q_{1}\right)=-r_{1} \\
M_{2} \ddot{z}_{2}+\eta_{2}\left(\dot{z_{2}}-\dot{q}_{2}\right)+c_{2}\left(z_{2}-q_{2}\right)=r_{2}
\end{array}\right.
$$

These equations are simplified by introducing the wellknown notation:

$$
\frac{\eta_{1,2}}{\mathrm{M}_{1,2}}=2 k_{1,2}, \frac{c_{1,2}}{\mathrm{M}_{1,2}}=\omega_{1,2}^{2},
$$

After substitution and elementary transformations, the differential equations take the following form:

$$
\left\{\begin{array}{l}
\ddot{z}_{1}+2 k_{1} \dot{z}_{1}+\omega^{2}{ }_{1} z_{1}=\omega^{2}{ }_{1} q_{1}+2 k_{1} q_{1}-\frac{1}{\mathrm{M}_{1}} r_{1} \\
\ddot{z}_{2}+2 k_{2} \dot{z}_{2}+\omega^{2}{ }_{2} z_{2}=\omega^{2}{ }_{2} q_{2}+2 k_{2} \dot{q}_{2}-\frac{1}{\mathrm{M}_{2}} r_{2}
\end{array}\right.
$$

Forces equivalent to the moment of braking and inertial forces are described by the dependence [4]:

$$
r_{1,2}= \pm \frac{h_{u}}{L} \varphi\left[\begin{array}{l}
M g \delta_{0}(t)+c_{1}\left(z_{1}-g_{1}\right)+ \\
+\eta_{1}\left(\dot{z}_{1}-\dot{g}_{1}\right)+c_{2}\left(z_{2}-g_{2}\right)+ \\
+\eta_{2}\left(\dot{z}_{2}-\dot{g}_{2}\right)
\end{array}\right]
$$

In equation (5), taking into account braking with full use of adhesion forces and instantaneous application of 
braking forces $\delta_{0}(t)$, the unit Heaviside function is displayed, expressing a unit jump in the form:

$$
\delta_{0}(t)=\left\{\begin{array}{l}
0 \text { for } t<0 \\
\infty \text { for } t>0
\end{array}\right.
$$

The obtained equations reveal a significant feature of vehicle vibrations with full use of adhesion forces, namely, when braking forces are applied, a close interdependence of vertical vibrations of the front and rear sprung masses arises.

\section{ESTIMATED PARAMETERS OF BRAKING PROPERTIES TAKING INTO ACCOUNT VIBRATIONS}

When the vehicle's sprung masses oscillate, the vertical load, which is formed in the contact of the wheels with the road, also changes. When the vertical load changes, the braking forces also change, which leads to a deterioration in the braking dynamics of the vehicle.

The magnitude of the braking force $\mathrm{P} \tau 1.2$ in contact of the wheels with the road is determined as:

$$
P_{\tau 1,2}=R_{z 1,2} \varphi_{x},
$$

where $\varphi_{x}$ is the coefficient of adhesion of the tires to the supporting surface.

The normal reaction in contact of the wheel with the road, taking into account the resulting vibrations, is determined:

$$
R_{z 1,2}=M_{1,2}\left(g \pm \ddot{z}_{1,2}\right),
$$

where $g$ - acceleration of gravity; $\ddot{z}_{1,2}$ - acceleration of the front and rear sprung masses of the vehicle.

The amount of deceleration, taking into account the vibrations of the sprung masses, can be determined:

$$
j=\left(g \pm \ddot{z}_{0}\right) \varphi_{x},
$$

where $\ddot{z}_{0}$ - vertical acceleration of the center of gravity of the sprung masses.

$$
\ddot{z}_{0}=\frac{\ddot{z}_{2} a+\ddot{z}_{1} b}{a+b}
$$

The change in stopping distance when impacted by an uneven road can be seen through the loss of kinetic energy when driving.

The kinetic energy of a car moving in braking mode under the influence of road surface irregularities is spent on the work of friction in contact of the wheels with the road, on overcoming the horizontal component $R_{x}$, arising from the action of the normal reaction $R_{\mathrm{z}}$, and on the excitation of vibrations of sprung and unsprung masses:

$$
\frac{M V_{a}^{2}}{2}=S_{t} R_{z} \varphi_{x} \pm E_{R x}+E_{p},
$$

where $\frac{M V_{a}^{2}}{2}-$ kinetic energy of a car moving in braking mode; $V_{a}$ - travel speed; $S_{t} R_{z 1.2} \varphi_{x}-$ friction work in contact of the wheels with the road; $S_{t}$ - braking distances; $E_{R x}$ - energy consumption to overcome the horizontal component $R_{x} ; E_{p}$ - energy consumption for vibrations of sprung masses.

Energy costs to overcome the horizontal component $\mathrm{R}_{\mathrm{x}}$ can be defined as [6]:

$$
E_{R x} \approx 0,063 \frac{c_{1.2}}{M} M v z_{0}^{2},
$$

where $v$-disturbance frequency.

Disturbance frequency:

$$
v=\frac{V_{a}}{l_{H}},
$$

where $l_{H}$-irregularity length.

Energy consumption for vibrations of sprung masses:

$$
E_{p}=P_{p} z_{0}
$$

where $P_{p}$ - work spent on vibrations.

$$
P_{p}=0,392 q_{0} \omega^{2} M
$$

where $\omega$ - frequency of natural vibrations.

$$
\omega^{2}=\frac{c}{M}
$$

Braking distances:

$$
S_{t}=\frac{M V_{a}^{2}-2\left(E_{p} \pm E_{R x}\right)}{2 R_{z 1,2} \varphi_{x}} .
$$

Deceleration time provided that the final speed is equal to zero:

$$
t=\frac{2 M V_{a}^{2}-2\left(E_{p} \pm E_{R x}\right)}{2 V_{a} M(g \pm \ddot{z}) \varphi_{x}} .
$$

\section{THEORETICAL RESEARCH}

For the theoretical study, a car was chosen, which is characterized by the following parameters:

- car base L = 2900 mm;

- distance from the center of mass of the vehicle to the front axle $\mathrm{a}=1500 \mathrm{~mm}$;

- distance from the center of mass of the vehicle to the rear axle b = $1400 \mathrm{~mm}$;

- coefficient of normal suspension stiffness $c_{1,2}=3$ $\mathrm{MN} / \mathrm{m} ; \mathrm{c}_{1,2}=6 \mathrm{MN} / \mathrm{m} ; \mathrm{c}_{1,2}=9 \mathrm{MN} / \mathrm{m} ; \mathrm{c}_{\mathrm{p}}=12 \mathrm{MN} / \mathrm{m}$;

- coefficient of normal stiffness of tires $c_{t}=1,3 \mathrm{MN} / \mathrm{m}$;

- vehicle center of mass $h_{0}=750 \mathrm{~mm}$;

- sprung vehicle weight $\mathrm{M}=1700 \mathrm{~kg}$.

The adhesion coefficient is taken to be $\varphi_{\mathrm{x}}=0.7$, unevenness height $\mathrm{Q}=0,05 \mathrm{~m}$. 
As a disturbing external influence during braking, an impulse irregularity was chosen, the mathematical description of which is characterized by the function[7], [8]:

$$
\left\{\begin{array}{c}
\mathrm{q}=0, \text { for } \mathrm{t}<t 1, t>t_{2} \\
\mathrm{q}=\mathrm{Q}, \text { for } \mathrm{t}_{1} \leq \mathrm{t} \leq \mathrm{t}_{2}
\end{array}\right.
$$

where $\mathrm{Q}$ - unevenness height; $\mathrm{t}_{2}, \mathrm{t}_{1}$ - the travel time of the unevenness.

The variable parameter in the study by the mathematical model is the suspension stiffness coefficient, which for cars is in the range $c_{1,2}=3-12 \mathrm{MN} / \mathrm{m}$.

The solution of the system of equations (4), allows you to obtain the values of the acceleration of the sprung mass, which are used in formulas (7) - (18) to determine the estimated parameters of the braking properties.

The results of calculating the main values are presented in Table 1.

\begin{tabular}{|c|c|c|c|c|}
\hline \multirow{2}{*}{ Nomination } & \multicolumn{4}{|c|}{ 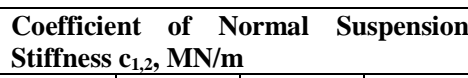 } \\
\hline & 3 & 6 & 9 & 12 \\
\hline $\begin{array}{l}\text { Reduced stiffness of the } \\
\text { suspension } C, \mathrm{MH} / \mathrm{M}\end{array}$ & 1,18 & 2,14 & 2,27 & 2,35 \\
\hline $\begin{array}{l}\text { Moving the sprung } \\
\text { mass } Z, \mathrm{~m}\end{array}$ & 0,56 & 0,61 & 0,64 & 0,65 \\
\hline $\begin{array}{l}\text { Acceleration of the } \\
\text { sprung mass } \ddot{Z}, \mathrm{~mm} / \mathrm{s}^{2}\end{array}$ & 6,5 & 6,9 & 7,2 & 7,5 \\
\hline Braking distances $S_{t}, \mathrm{~m}$ & 6,56 & 7,43 & 8,26 & 9,3 \\
\hline Deceleration $j, \mathrm{~mm} / \mathrm{s}^{2}$ & 2,010 & 1,766 & 1,584 & 1,402 \\
\hline Braking time $t, \mathrm{~s}$ & 2,38 & 2,71 & 3,01 & 3,4 \\
\hline
\end{tabular}

TABLE 1 - CALCULATION RESULTS

For clarity, the calculated data plotted the dependence of the obtained values on the suspension stiffness coefficient (Fig. 2).

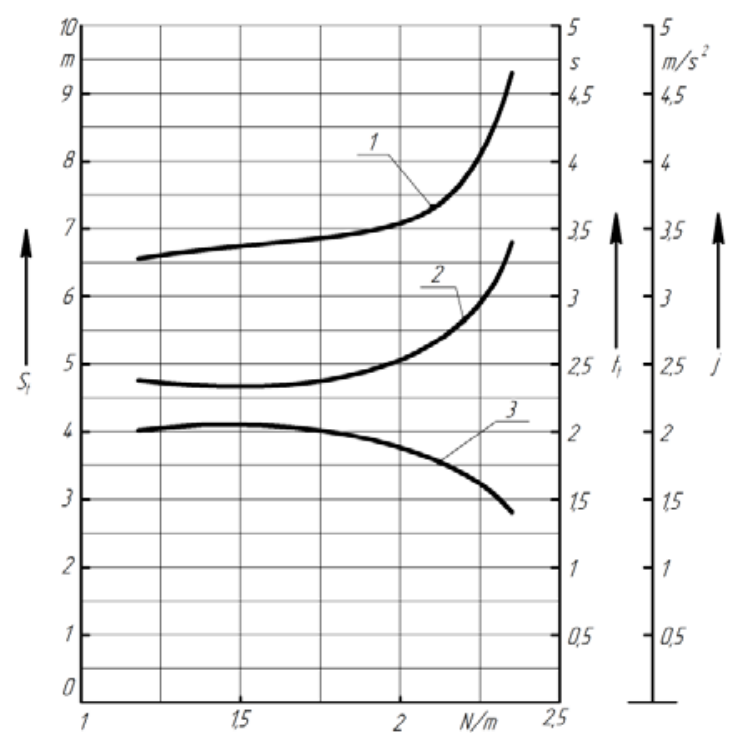

1 - braking distances 2 - braking time 3 - car deceleration

Fig. 2. Influence of the suspension stiffness coefficient on the estimated parameters of braking properties.

\section{CONCLUSIONS}

The carried out theoretical studies allow us to conclude that when braking on an uneven road with full use of adhesion forces, an increase in the coefficient of normal stiffness leads, as a consequence, to a change in the arising oscillations of the sprung masses of the vehicle, leading to an increase in the braking distance and braking time of the vehicle, and to a significant decrease in deceleration, which corresponds to deterioration of the braking dynamics of cars.

In addition, it should be noted that when braking on an uneven road, the braking properties are reduced, in contrast to braking on a flat road.

\section{REFERENCES}

[1] V.K.Vakhlamov, Automobiles: Operational properties. textbook for stud. higher studies. institutions. 3rd edition., P. M.: Publishing house. Center "Academy", 2007, 238 p.

[2] V.F.Yukhimenko and A.A. Yatsenko, Vehicle safety: study guide. Vladivostok: Publishing house of VSUES, 2009. 208 p.

[3] A.Sh. Khusainov, Passive safety of the car: a tutorial. Ulyanovsk: UISTU, 2011, 89 p.

[4] A.A. Enaev, Fundamentals of the theory of vibrations of a car during braking and its applications. M.: Mechanical Engineering, 2002, 341 p.

[5] N. N.Yatsenko and A. A.Enaev, Oscillations of the car during braking. Irkutsk: Irkutsk University Publishing House, 1989, 248 p

[6] N. Ya.Govorushchenko, Fundamentals of the theory of car exploitation. K .: Vischa school, 1971, 240 p.

[7] N.N. Yatsenko and O.K. Prutchikov, Smooth running of trucks. M.: Mechanical Engineering, 1969, 218 p.

[8] M. Ya. Pevzner and G. G.Gridasov, Oscillations of the car. M.: Machine building, 1979, 208 p. 